\title{
The Delta Connectome: A network-based framework for studying connectivity in river deltas
}

\author{
Paola Passalacqua ${ }^{\mathrm{a}, *}$ \\ ${ }^{a}$ Department of Civil, Architectural, and Environmental Engineering and Center for \\ Research in Water Resources, The University of Texas at Austin, 301 E. Dean Keeton St. \\ STOP C1700 Austin, TX 78712-2100, USA
}

\begin{abstract}
Many deltas, including the Mississippi River Delta, have been losing land at fast rates compromising the safety and sustainability of their ecosystems. Knowledge of delta vulnerability has raised global concern and stimulated active interdisciplinary research as deltas are densely populated landscapes, rich in agriculture, fisheries, oil and gas, and important means for navigation.

There are many ways of looking at this problem which all contribute to a deeper understanding of the functioning of coastal systems. One aspect that has been overlooked thus far, yet fundamental for advancing delta science is connectivity, both physical (how different portions of the system interact with each other) as well as conceptual (pathways of process coupling).

In this paper, I propose a framework called Delta Connectome for studying connectivity in river deltas based on different representations of a delta as a network. After analyzing the classic network representation as a set of nodes (e.g., bifurcations and junctions or regions with distinct physical or statistical behavior) and links (e.g., channels), I show that from connectivity considerations the delta emerges as a leaky network that continuously exchanges fluxes of matter, energy, and information with its surroundings and evolves over time. I explore each network representation and show through several examples how quantifying connectivity can bring to light aspects of deltaic systems so far unexplored
\end{abstract}

\footnotetext{
* Corresponding author

Email address: paola@austin.utexas.edu (Paola Passalacqua)
} 
and yet fundamental to understanding system functioning and informing coastal management and restoration. This paper serves both as an introduction to the Delta Connectome framework as well as a review of recent applications of the concepts of network and connectivity to deltaic systems within the Connectome framework.

Keywords: deltas, distributary networks, topology, graph, connectivity, hydrodynamics, morphodynamics

\section{Introduction: Why study connectivity in deltaic systems?}

Deltaic systems show tremendous variability of shape and structure (Figure 1); their location, at the boundary between land and water, makes them prone to dynamic spatial and temporal disruptions due to environmental factors such

5 as waves, wind, and tides. The relevance of deltaic systems goes well beyond aesthetics; home to wetlands and hot-spots of biological productivity, deltas are ideal environments for fish and agricultural productivity, oil and gas resources, and navigation pathways. It is natural that because of all these factors and a tendency for people to settle in fertile soils in proximity of sources of water, deltas are home to more than 500 million inhabitants (Giosan et al., 2014).

International attention has been recently focused on deltaic systems; their low elevation gradients and the natural and anthropogenic subsidence they are subject to (Syvitski et al., 2009) make them vulnerable to relative sea-level rise (actual sea level plus subsidence) (Horton et al., 2014; Jevrejeva et al., 2014), raising concern in numerous areas of the world, including the Mississippi River delta and the highly populated South Asian deltas (Ericson et al., 2006).

Experiments have shown that under the right conditions deltas are able to match forcings such as sea-level rise. For example, an increase in sea level does not necessarily cause shoreline retreat (land loss) and aggradation of the delta top is possible as long as enough sediment is supplied to the system (Helland-Hansen and Martinsen, 1996; Muto, 2001; Carvajal et al., 2009; Martin et al., 2009; Sverre et al., 2009; Paola et al., 2011). 

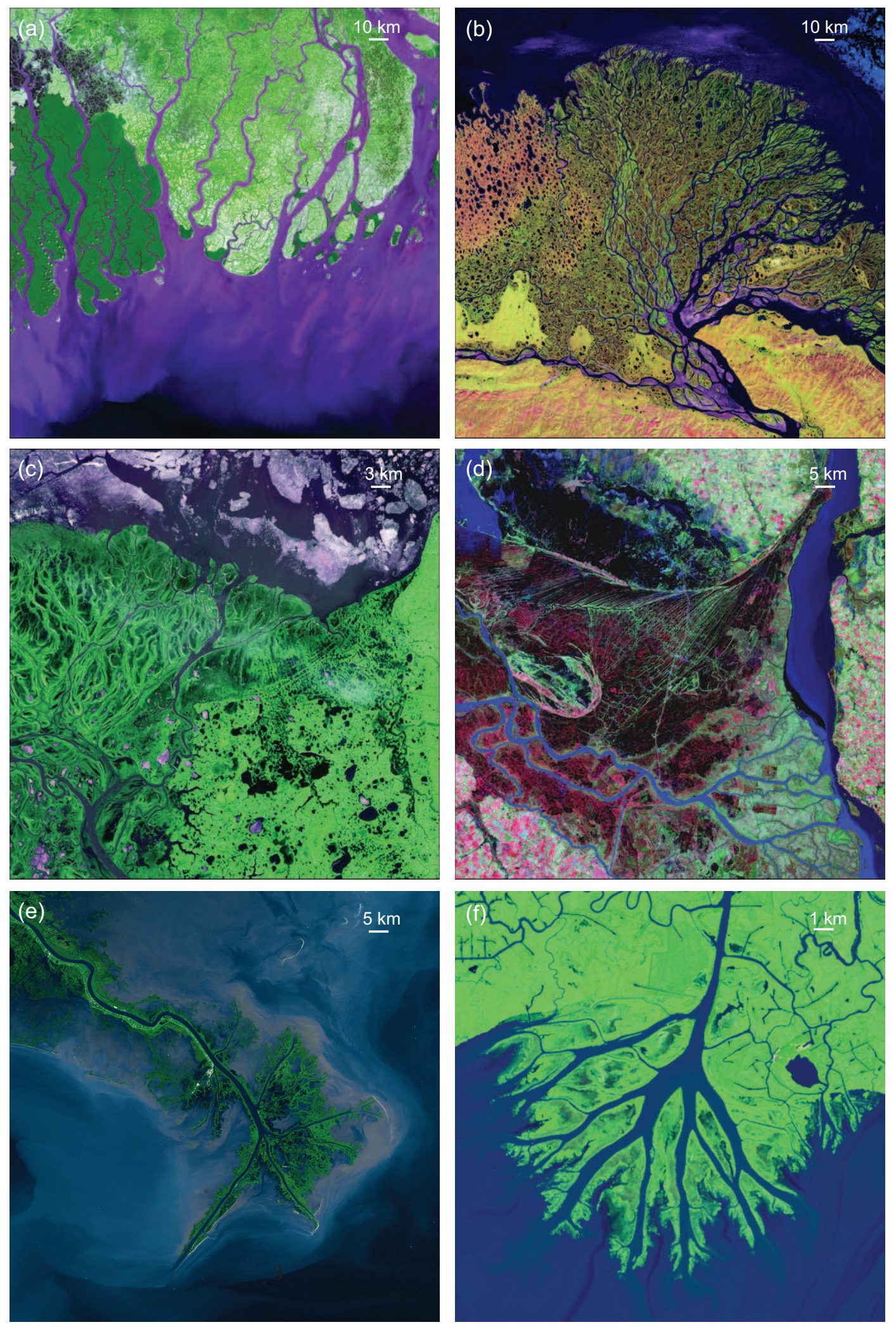

Figure 1: Examples of delta systems. (a) Portion of the Ganges-Brahmaputra-Meghna Delta; (b) Lena Delta; (c) Yukon Delta; (d) Parana Delta; (e) Mississippi River Delta; (f) Wax Lake Delta. Images from NASA Visible Earth. 
Why then are so many deltaic systems in danger? The tremendous development of dams and reservoirs in many parts of the world contributes to the sinking of many deltaic systems (Giosan et al., 2014). Flood management interventions, such as the construction of levees, and cutting of channel networks into wetlands for transport and draining further exacerbate this problem. For example in the Mississippi River delta, a lowland system where connectivity of channel and floodplains should be high (Fryirs, 2013), the construction of levees has contributed to the loss of $1 / 3$ of the land since colonization (Craig et al., 1979; Gagliano et al., 1981; Kesel, 1989; Day et al., 2000, 2007) as sediment is routed to the Gulf of Mexico by a very efficient pipe flow (Falcini and Jerolmack, 2010; Paola et al., 2011; Falcini et al., 2012). Problems related to anthropogenic structures are not unique to the Mississippi River delta; for example, in the 35 Ganges-Brahmaputra-Meghna delta (GBMD) increasing inundation has been recently attributed to the amplification of the tidal signal due to the construction of embankments (Pethick and Orford, 2013) and high subsidence rates have been measured at aquaculture facilities in the Yellow River delta (Higgins et al., 2013). Engineered flood protections disconnect the river from its floodplain resulting in increased vulnerability of delta systems (Temmerman and Kirwan, 2015).

There are several ways to understand delta processes and response to perturbations; efforts have been focused on numerical (e.g., Seybold et al., 2007, 2009; Geleynse et al., 2010; Rowland et al., 2010; Sassi et al., 2012; Liang et al., ${ }_{45}$ 2015b) and experimental modeling (e.g., Hoyal and Sheets, 2009; Kim et al., 2009; Martin et al., 2009; Reitz et al., 2010) as well as on the analysis of field observations (e.g., Shaw and Mohrig, 2014; Shaw et al., 2013) and of remotely sensed imagery (e.g., Brakenridge et al., 2013; Passalacqua et al., 2013; Geleynse et al., 2015) to gain an understanding of delta formation and evolution under a suite of initial and boundary conditions. Most of this research, though, has focused on one specific portion of the system, for example channels or islands, without quantifying their connectivity (Hiatt and Passalacqua, 2015).

Connectivity has been the subject of a significant number of recent papers in 
the hydrologic literature (e.g., Pringle, 2003; Ali and Roy, 2009; Bracken et al., 2013) that point at three main mechanisms; structural connectivity (driven by physical adjacency of a system's elements (Bracken et al., 2013)), functional connectivity (also referred to as process-based; processes that control the directionality and magnitude of fluxes across a landscape (Bracken et al., 2013)), and process connectivity (flow of information among a system's drivers, where information is a reduction in the uncertainty of a variable's state (Ruddell and Kumar, 2009a; Larsen et al., 2012; Miller et al., 2012; Wang et al., 2012)). The analysis of these connectivity mechanisms is recognized as a key step to inform watershed management decisions and hydrologic prediction (e.g., Western et al., 2001; Bracken et al., 2013).

In connectivity analyses the system can be represented as a network; a set of nodes and of links connecting them. Network theory, the mathematical field that analyzes networks, their structure, and dynamics, has been widely applied across disciplines (Newman et al., 2006), from computer science, to biology, to the human brain, and it is beginning to appear in the geomorphology literature (see Heckmann et al. (2015) and Phillips et al. (2015) for recent reviews). The hydrologic literature offers many examples of network analysis applied to watersheds and river networks. From early work to recent applications, the connection between river network topology and watershed hydrologic response has been tackled (e.g., Gupta and Mesa, 1988; Rodriguez-Iturbe and Rinaldo, 75 1997; Biswal and Marani, 2010; Gupta et al., 2010; Zaliapin et al., 2010), as well as its effect on ecosystem, sediment, nutrients, and riparian vegetation (e.g., Benda et al., 2004a,b; Kiffney et al., 2006; Lowe et al., 2006; Sklar et al., 2006; Czuba and Foufoula-Georgiou, 2014). The development of similar knowledge on the relationship between the network structure and the dynamics of water, so solids, and solutes in coastal systems is in its infancy.

Is an analysis of connectivity (and dis-connectivity) needed in deltas? There are several issues relevant to deltaic systems that require knowledge of connectivity. Deltaic channels distribute water, sediment, and nutrients; their distributary network emerges from processes such as mouth-bar deposition and 
avulsions and the contribution of environmental factors such as tides and waves. Yet, we do not completely understand the relationship between network form and function. We lack an understanding of how water and sediment fluxes are partitioned and of where hotspots of nutrient delivery and uptake are located. The connectivity between surface water and groundwater is largely unknown, as well as the connectivity of surface patterns and the stratigraphic record. Couplings among delta variables are only qualitatively, rather than quantitatively known. On the other hand, management decisions and coastal restoration require knowledge on how different portions interact with each other across scales (Paola et al., 2011).

The recent availability of satellite imagery over much of the Earth (Syvitski, 2006) has greatly improved the quantitative analysis of geomorphic features. Over smaller spatial extents, techniques such as lidar have increased the capability of remotely capturing geomorphic processes at fine scales (Passalacqua et al., 2015). Advanced tools for the extraction of geomorphic features from remotely sensed data of coastal environments are now available (Shaw et al., 2008; Geleynse et al., 2012; Isikdogan et al., 2015) and physical and numerical modeling of deltaic systems have been underway for more than a decade. Techniques for field data acquisition have also been improved and new techniques have been developed (e.g., multi-beam sonar, green lidar, ADCP sensors), providing detailed bathymetry and flux data. Also, research in river network structure and watershed connectivity has been pursued for more than a decade, which provides us with good background knowledge and tools on how to study connectivity in the upstream counterpart of delta networks, i.e. river tributary networks (e.g., Bracken et al., 2013; Fryirs, 2013; Czuba and Foufoula-Georgiou, 2014). Also, ideas can be taken from other fields where complex networks have been analyzed (see Newman (2010) for a review).

Motivated by these factors, in this paper I propose the Delta Connectome as a framework to study deltaic systems by exploring their connectivity in structure, dynamics, and process, which relies on the representation of the delta sys115 tem as a network that continuously exchanges fluxes of matter, energy, and/or 
information with its surroundings and changes over time. I introduce the Delta Connectome framework with an analogy to brain networks and a discussion on scale and observations (Section 2) and then apply it through different representations of the delta system as a network, reviewing also recent network theory and connectivity work in delta systems (Section 3). I then discuss the relevance of a connectivity approach for coastal sustainability and provide ideas for future applications of the Connectome framework (Section 4). Finally, the conclusions of this work are presented (Section 5).

\section{How to quantify connectivity in deltaic systems: The Delta Con- nectome framework}

\subsection{Inspiration for the Delta Connectome: Deltas as complex networks}

The Human Connectome framework was introduced by Sporns et al. (2005) to advance knowledge of the structure and function of the human brain by detailed mapping of neural connections. This is not a trivial task given the number of neurons and connections that on average characterize the complex network of the human brain $\left(10^{11}\right.$ neurons and $10^{15}$ connections (Sporns et al., 2005)). From the microscale or scale of single neurons, to the mesoscale of neuronal groups or populations, to the macroscale of brain regions and regional pathways, the brain shows multiple levels of connectivity whose quantification requires appropriate techniques for data collection and analysis (Sporns et al., 2005). In addition to the wide range of spatial scales, the brain goes through tremendous development through time from the early stages of the embryo up to adult life and is subject to changes and perturbations. These characteristics are not unique to the human brain as many systems across disciplines can be viewed as complex networks (Newman et al., 2006).

Deltas are seldom analyzed with network theory tools; however, their complexity and multi-scale (spatial and temporal) characteristics would suggest they are in fact complex networks. A wide range of spatial scales contribute to delta functioning, from the interactions at the scale of grains and particles (the neu- 
rons) to the network of channels that transport water, sediment, and nutrients (the regional pathways) and regulate the system's response to forcings such as sea-level rise and subsidence. The channel network can be complex and characterized by the presence of loops and multiple paths between the apex and the shoreline. This characteristic makes deltas 'networks' as opposed to 'trees' where a unique path exists between a source and a sink (see Newman (2010) and references therein for more information on networks and trees). Tributary river networks are an example of the latter. Deltas also continually evolve and change in time; mechanisms such as channel avulsions, for example, change the network structure, essentially rewiring the system by favoring new pathways and abandoning previous ones (Slingerland and Smith, 2004; Kleinhans et al., 2013). Environmental factors such as wind, tides, and waves vary patterns of inundation daily and contribute to the transport of sediment and solutes.

A connectivity analysis consists of identifying a set of objects (e.g., locations or variables) and the connections among them. Methods to quantify connectivity often rely on network representations of the system, as objects can be thought of as nodes of a network and connections or physical dependencies as network links. Mathematically, an adjacency matrix in its simplest form captures whether two nodes are connected. The adjacency matrix can also include link directionality, in which case the matrix is not symmetric, and strength of the connection, in which case weights are associated to each link in the adjacency matrix. The advantage of relying on the representation of a system as a network and its related mathematical analysis is that the same tools can be applied to different network representations and over multiple scales. Essentially, while the mathematical representation is overall the same, the definition of nodes and links dictates what aspect of the system is captured and thus what type of connectivity can be measured.

With the Delta Connectome framework I extend the term 'network' from the rigid definition given above, where a set of nodes and their links completely describes the system, to the one of a network where physical locations exchange fluxes of matter, energy, and information, essentially embedding the network 
in a continuous field where it is also able to evolve and reconfigure itself over time. The network representations are here designed to quantify aspects of physical connectivity among different portions of the system (physical adjacency - structural connectivity) and to analyze how that adjacency affects fluxes of water, sediment, nutrients (functional connectivity) and information (process connectivity).

Given the wide range of scales that contribute to delta functioning, at what scale can connectivity be quantified? Below, I briefly review the approaches that are commonly used to study deltas and the types of observations that are currently available to quantify connectivity.

\subsection{At what scale can connectivity be quantified? Approaches commonly used to study deltas}

Commonly used approaches to study deltas include numerical and physical experiments, field and theoretical studies, as well as the analysis of remotely sensed observations, which all provide useful information to perform a connectivity analysis of delta systems.

Numerical models commonly rely on governing equations of delta formation and evolution based on a conservation approach within and across a control volume of interest. High fidelity modeling approaches such as Delft3D (Lesser et al., 2004), for example, solve the Navier-Stokes equations. In this case, limitations to the model grid resolution and the amount of flow detail directly resolved come from the computational costs associated with the simulations. Modeling results provide a range of delta morphologies, simulated under a variety of boundary conditions, and related synthetic observations of water and sediment fluxes, which can be used to quantify physical and process connectivity. The scale of analysis is commonly the macroscale of channels and islands, while microscale interactions are usually embedded in laws, such as those governing sediment transport. Lagrangian approaches to delta modeling exist, in which commonly not all details of the system are captured (Liang et al., 
and their contribution to delta formation and evolution.

Model results should be compared to other types of observations (e.g., from the field) with robust metrics. While metrics for the assessment of the hydrodynamic component are overall well defined (Liang et al., 2015a), robust metrics tions in reproducing these processes in physical or numerical models. Spatial and temporal extent of field surveys depend on the available resources. Even in systems of reasonable size, for example the Wax Lake Delta $($ WLD $)(\approx 100$ $\mathrm{km}^{2}$ ), the collection of observations at the network scale is challenging due to the 235 highly dynamic conditions that characterize deltaic systems. The rapid change in hydrodynamic conditions due to environmental forces such as wind and tides, 
often prevents the collection of observations over the whole system under the same hydrodynamic and morphodynamic conditions unless enough instruments are available to take measurements at different locations simultaneously. Mea-

above, the physical network representations are defined at the scale of channels and islands rather than the microscale of single particles. These network repre- 
sentations are not meant to be the only ones possible, but rather offer examples of application of the Delta Connectome framework and inspire further work in

\section{Application of the Delta Connectome framework}

\subsection{The delta as a network of channels}

Perhaps the most classic way of representing a delta as a network is its distributary network of channels. In this representation, we can view channel the channels connecting them as network links (Figure 2). Properties of the channels, such as their width, can be used as weights to express a measure of strength of network links (Passalacqua et al., 2013). Flow directions along channels indicate link directions. A representation of the delta as a network of channels can be used to quantify the transport of water, sediment, and solutes via channelized flow to the shoreline and to island interiors (if the secondary network of channels is included), and travel times through the system.

Several early and recent studies have focused on delta distributary channel networks to identify robust metrics able to describe them quantitatively 285 (Smart and Moruzzi, 1971; Edmonds et al., 2011; Tejedor et al., 2015a,b), predict their development based on simple laws (Syvitski, 2006; Edmonds and Slingerland, 2007; Jerolmack and Swenson, 2007; Syvitski and Saito, 2007; Wolinsky et al., 2010), quantify the controls exerted by grain size (Caldwell and Edmonds, 2014), and analyze network response to forcings such as sea-level rise and subsidence the majority of these studies; however, knowledge derived from them, including metrics, can inform connectivity analyses and is reviewed below.

In the early work of Smart and Moruzzi (1971), the network was analyzed as a directed graph and its characteristics quantified based on a directed adjacency matrix. The directed adjacency matrix accounts for the directionality of the link between two nodes $i$ and $j$ : location $a_{i j}$ is assigned a value equal to 1 only if the 


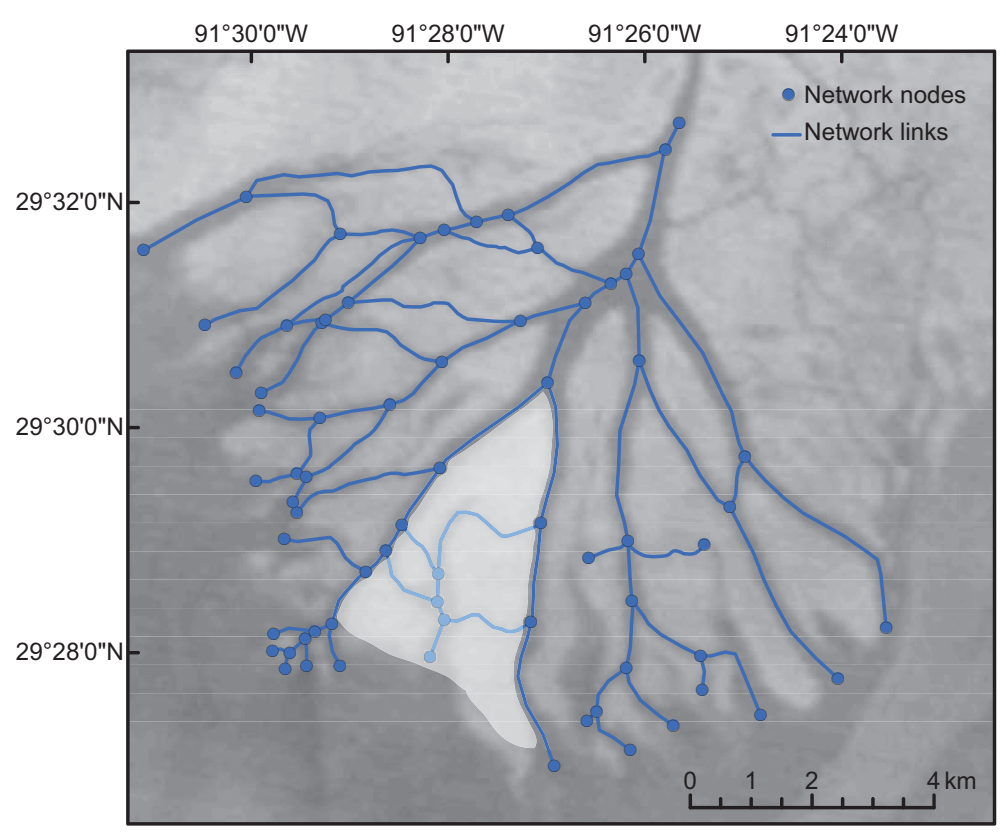

Figure 2: Example of delta channel network. Network links (lines) and nodes (circles) are overlaid on Landsat data of the Wax Lake Delta. The low water level conditions at which the image was taken allow secondary channels within islands to be detected. An example of island is indicated by the shaded polygon. Image specifications: LANDSAT 5 TM+ image from 02 January 2011 at $30 \mathrm{~m}$ resolution obtained from the USGS Global Visualization Viewer (available online at http://glovis.usgs.gov/). The extracted channel network is part of the WLD Network Evolution Database developed as part of the Delta Dynamics Collaboratory at Wax Lake Delta. 
flow is directed from node $i$ to node $j$ and a value equal to 0 if the flow is directed in the opposite direction. Only the primary network of channels was included in this study, while secondary channels draining to island interiors were neglected. Metrics analyzed by the authors included the number of alternative paths from the apex to the shore and the recombination factor, defined as the ratio of the number of junctions to the number of bifurcations to capture the loopiness of the network. The comparison of five natural systems (Colville, Irrawaddy, Yukon, Niger, Parana) to random networks with the same number of nodes and links showed that delta networks carry distinct network characteristics with respect to random connections and that some degree of similarity among delta systems could be captured based on the defined metrics.

The same directed graph representation of the primary channels was also adopted by Tejedor et al. (2015a,b), who proposed a set of metrics to quan-

310 vulnerability as lack of or reduced delivery of fluxes to the shore (connections to island interiors were neglected), the authors used graph theory and constructed vulnerability maps for two delta networks (Wax Lake Delta and the Niger Delta). The authors then extended their analysis to seven delta networks 315 tions based on the topological configuration of the network and the assumption of a general downstream direction. It is worth noting that in the case of loops this operation is not trivial as links are not necessarily oriented in an obvious downstream direction. Furthermore, directions along delta channels may not be in flow direction due to tides.

Besides the above studies based on graph theory, other efforts have analyzed 
distributary channel networks to develop simple predictive laws of delta network evolution. Syvitski (2006) and Syvitski and Saito (2007) analyzed a large database of delta systems and derived the scaling of the number of distributary channels with river length and delta gradient and the distribution of channel width. Edmonds and Slingerland (2007) developed a predictive model of distributary network formation based on the process of mouth-bar deposition at the shoreline, ideas extended by Jerolmack and Swenson (2007) to include avulsions and the action of waves at the shoreline. The analysis by Wolinsky et al. (2010) led to the development of additional laws of delta growth and included the application of a box counting technique which showed fractality of the distributary network and the nonfractal nature of the delta shoreline.

Fractal dimension was also used as metric for comparison of five deltas (nu340 merical, experimental, and real systems) in the study by Edmonds et al. (2011). A representation of the delta as channel reaches (links) between bifurcation points (nodes) was used in the same study to estimate the sediment flux delivered by each channel at the shoreline, where the sediment flux was assumed to be proportional to the water discharge. The distribution of sediment flux delivered by channels to the shoreline was used to infer the stability of the distributary network; uniform distributions indicate stable network configurations, differently from cases in which most of the sediment is delivered by one channel, which likely lead to avulsions and changes in the network configuration.

Characteristics of the delta channel network have also been used in numerical modeling studies to quantify the effect of changes in initial conditions and boundary conditions. The study of Caldwell and Edmonds (2014) analyzed how grain size affects delta morphology. The results showed that increasing the grain size results in denser networks in deltas of more circular shape, while finer sediment systems are characterized by less channels and more elongated shapes. 355 Liang et al. (2016) quantified the delta channel network response to stressors such as sea-level rise and subsidence. In this case, the analysis of the network structure was used to quantify its dynamic response to a forcing. The results showed increased branching (denser network and higher connectivity) of the 
channel network with increased fractality and higher mobility in response to

Jerolmack (2009) developed a conceptual model to analyze the response of delta channel networks to the rapid mid Holocene sea level rise and its later deceleration. The model predicted initial aggradation and an increase in avulsion frequency with formation of large scale distributaries, followed by prograda365 tion, a decrease in the number of large distributaries, and an increase in small branching channels at the shoreline.

\subsection{The delta as a leaky network of channels and inter-channel islands}

The work described above analyzes delta systems by relying on their somewhat rigid representation as a network of channels. While this representation is commonly used, is it enough to capture the delta structure and dynamics? Many studies of river systems focus on the role of floodplains and their channel networks (e.g., Day et al., 2008; Rowland et al., 2009; Trigg et al., 2012) and the connectivity between channels and floodplains (e.g., Croke et al., 2013). Floodplains in river deltas are inter-channel islands; portions of land which are 375 bounded by channels (or by channels and the shoreline; e.g., the shaded polygon in Figure 2). Do islands participate in transport processes or are transport processes only active along the channel network? The delivery of sediment to the island interiors is a fundamental process to maintain and grow land and contrast the effect of subsidence and sea-level rise; thus, the analysis of the primary channel network may not be sufficient to characterize the transport of water, sediment, and nutrients through the system.

Recent literature has relied on islands as descriptors of the delta network structure. These efforts are briefly reviewed below before summarizing recent research that points at the importance of quantifying the connectivity between channels and islands and extends the notion of delta network to a leaky network of channels and islands. 


\subsubsection{The role of islands in delta networks}

The analysis of island characteristics may be as informative as the analysis of the distributary channel network, and perhaps even more as characteristics of the islands carry the signature of interactions among nearby channels. The metric nearest-edge distance (Edmonds et al., 2011), for example, is defined as the shortest distance to the nearest source of water (channelized or unchannelized) from any land pixel in the delta. This metric is essentially the inverse of drainage density as in very dense networks, where drainage density is high, nearest edge distance would be small and vice versa.

When applied to heterogeneous deltas, the analysis of island characteristics can highlight regions of the system characterized by distinct physical and statistical behavior (assuming that the delta has a large enough number of islands to yield robust statistics). In the GBMD, Passalacqua et al. (2013) found that island properties (roughness, neareast-edge distance, and area) showed power-law behavior, suggesting the lack of a characteristic island scale in deltaic systems. The statistical behavior of the analyzed properties distinguished the active portions of the delta from the inactive one, closely reproducing a physiographic zonation previously identified based on geological maps (Alam et al., 1990; Persits et al., 2001). Connectivity varied among different portions of the system, with the tidal zone (particularly within the mangrove zone) being the most connected, reflected in small island size and short nearest-edge distance (Figure $3(\mathrm{a})$ ).

Island characteristics can also be used to capture the delta response to forcings and disturbance; the study of Liang et al. (2016) showed decreasing island size and nearest-edge distance with increasing relative sea-level, in agreement with the increased branching of the channel network.

\subsubsection{The connectivity of channels and islands and the concept of a leaky net-} work

So far, we have covered two fundamental components of delta systems: channels and islands. While a classic view of the delta network comprises only its 


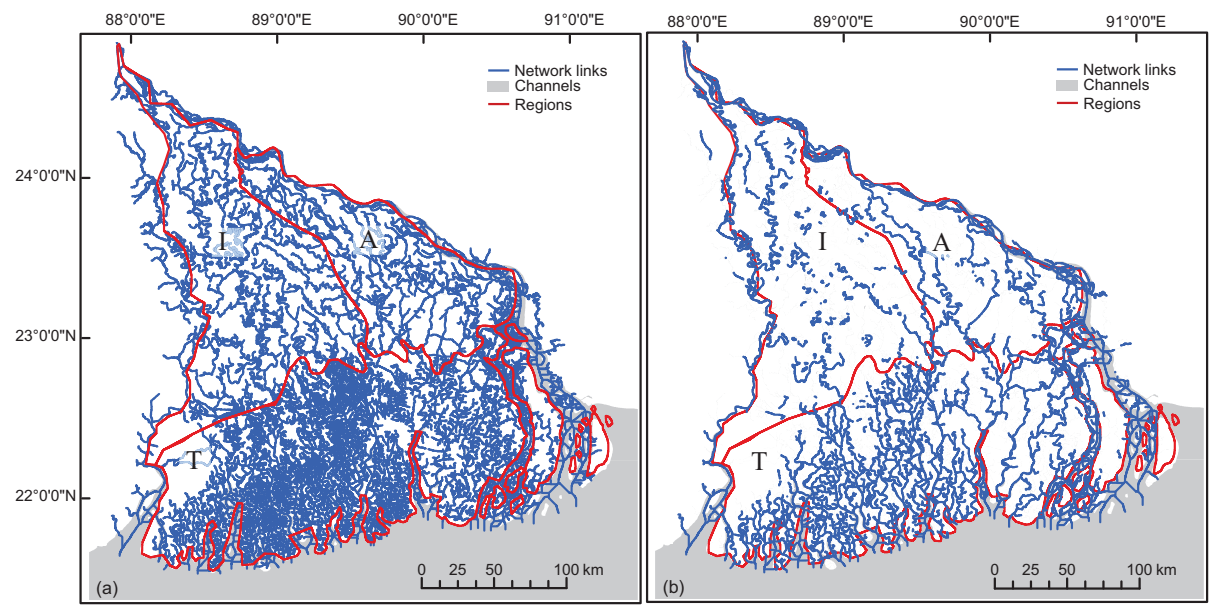

Figure 3: Connectivity analysis of the Ganges-Brahmaputra-Meghna Delta. (a) Map of channels and network links (channel centerlines) extracted from Landsat data (GeoCover TM1990 EditionMosaics, tiles N4520 and N4620). (b) The elimination of network links with width $\leq 60 \mathrm{~m}$ results in reduced network connectivity, particularly in the inactive zone (marked as $I)$. Channels connecting the upstream portion of the delta to the shoreline are predominantly narrow. The regional boundaries are marked as $T$ (tidal), $A$ (active), and $I$ (inactive) and they are from Alam et al. (1990) and Persits et al. (2001). Figure produced with data from Passalacqua et al. (2013). 
channels, the work reviewed above shows that islands, the 'negative' of channels, are useful descriptors of the structure of the system. Do islands play a role also in transport dynamics? Hiatt and Passalacqua (2015) measured the hydrological connectivity between channels and islands and found significant exchange between the two. Field observations collected at WLD showed that up to $\approx 50 \%$ of the water discharge of distributary channels can be transferred to islands (wetlands). Structural connectivity relies on a combination of secondary channels connecting the main distributary channel to the island interior and unconfined flow in the portion of the channel near the bay, favored by a transition in levee morphology from subareal and vegetated in the upstream portion of the island to subaqueous closer to the shore. Process-based connectivity is reflected in the impact of tides and wind on the magnitude and direction of these fluxes, as wind can significantly affect water levels and inundation (also shown by Geleynse et al. (2015)) and channels can show flow inversion due to tides.

Additional data collected at WLD during a series of tracer studies within an island showed convergence of fluxes towards the island interior and significant discharge from the island to the bay. Flow in islands is affected by tides to a higher degree than channels, resulting in higher estimates of hydraulic residence time within islands than in channels. Based on these findings, Hiatt and Passalacqua (2015) proposed a conceptual model of channel-island connectivity in delta systems (Figure 4) where both channels and islands are considered portions of the same hydrological network. An interesting aspect of this work, that merits further analysis in the future, is the combination of distributary (channels) and tributary (islands) character of the delta network, which suggests that fluxes are spread from the delta apex to the shoreline along channels, but converge towards island interiors (also noted by Shaw et al. (2016)) as in a tributary network (visible in the island secondary channels in 445 Figure 2 in correspondence of the shaded polygon).

The conceptual model of network proposed by Hiatt and Passalacqua (2015) (Figure 4) does not fit the rigid definition of network as a set of nodes and of 
links. Although some nodes and links of interest can be identified, the main characteristic of the channel-island network is its leakiness and the importance that off-channel dynamics play in delta functioning. This finding motivates the extension of the concept of 'network' to the one of a leaky network where matter, energy, and information are exchanged beyond the distributary channel network.

As noted by Liang et al. (2016), metrics to capture connectivity in delta systems are lacking. The authors proposed a framework to categorize delta metrics based on the type of characteristic they measure; whether it is a bulk property (e.g., delta area), a spatial distribution (e.g., the distribution of island size or channel width), or a temporal distribution (e.g., the timescale of avulsions). The metrics were also organized based on the object each metric is commonly applied to or was designed for, i.e. channels, islands, shoreline, delta surface, and subsurface. Not surprisingly, most of the metrics in all three categories have been developed for or applied to channels. The other result that emerged from this metric analysis is that almost no metric exists to quantify the connectivity among different portions of the delta. As mentioned above, deltas are usually analyzed as compartments rather than connected systems.

One exception is represented by the nourishment area, metric originally proposed by Edmonds et al. (2011). Analogously to the role played by drainage area in tributary systems (the portion of the watershed that drains to a given location), the nourishment area represents the amount of land fed by the sediment flux transported at a given location. In the application of Edmonds et al. (2011) the metric was calculated at a set of points along the channels by assuming symmetric spreading of fluxes downstream of any location, which resulted in a relationship between distance from the shore $L$ and nourishment area $A$ as $A \sim L^{2}$.

Liang et al. (2016) revisited the concept of nourishment area to quantify the channel-island connectivity identified by Hiatt and Passalacqua (2015). The authors relied on the lagrangian model DeltaRCM (Liang et al., 2015b) to track particle spreading from any location along the channel network. Based on their 


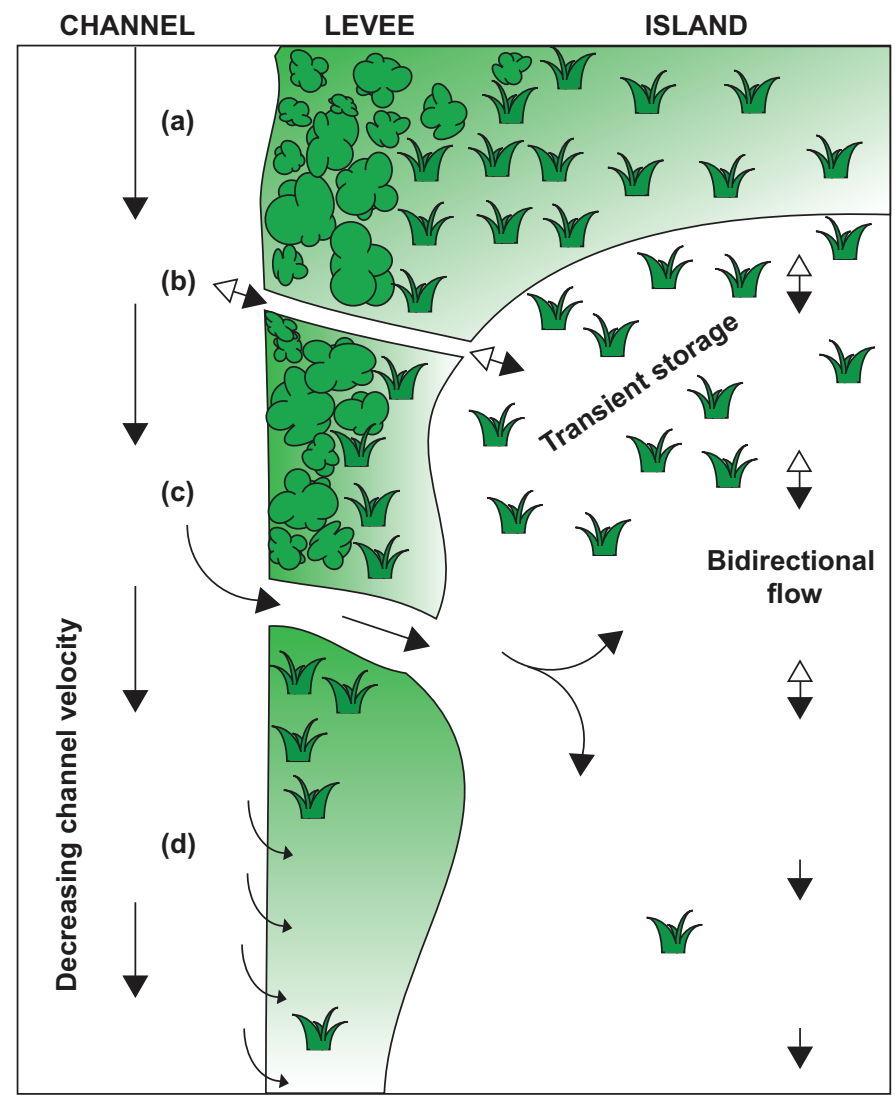

Figure 4: Channel-island connectivity in deltas. The conceptual model developed by Hiatt and Passalacqua (2015) showing the connectivity between channels and island in a delta system as it varies from mainly driven by secondary channels (in correspondence to subaerial and vegetated levees (b) and (c)) to unconfined flow (in correspondence to subaqueous levees (d)). Also indicated are flow directions along channels (a) and islands, including areas where bi-directional flow is expected due to the influence of tides (e.g., (b)). Figure reproduced from Hiatt and Passalacqua (2015). 
results, Liang et al. (2016) proposed a conceptual model to quantify channel-

island connectivity based on the variation of the degree of channel confinement from upstream to downstream. In this case, the relationship between the distance from the shore $L$ and the nourishment area $A$ is given by $A \sim L^{\theta}$ where the exponent $\theta$ takes a value $<2$ for decreasing confinement towards the shore (increasing channel-island connectivity), a value $>2$ for increasing confinement towards the shore (decreasing connectivity; an unlikely behavior for delta systems), and a value of 2 in the case of constant degree of confinement. With this definition, the variation of channel-island connectivity can be quantified as a function of distance from the shore under a variety of boundary conditions.

The other existing metric that could be adapted to quantify connectivity is the synthetic sediment flux distribution at the shoreline, which was reviewed in Section 3.1. Although originally developed as a delta channel network metric (the delivery of sediment to the shore from channels (Edmonds et al., 2011)), the metric could be easily applied to the channel-island network and to the transport of nutrients. Liang et al. (2015a), for example, applied this metric to quantify the water fluxes at the shoreline and analyze the partitioning of water discharge delivered at the shoreline between channels and islands.

\subsection{The delta as a network of regions of different physical or statistical char-} acteristics

Another factor that contributes to the complexity of delta systems is the role played by environmental forcings such as discharge, wind, tides, and waves on the delta formation and evolution. Interest in identifying dominant forcings on delta morphology stimulated research early on. Wright and Coleman (1972) identified river discharge and wave strength among the fundamental drivers of delta morphology, initiating the well known ternary classification according to rivers, waves, and tides (Wright and Coleman, 1973; Galloway, 1975). Even if more complex classifications have been proposed since then (Elliot, 1986; Hart, 1995; Syvitski, 2006), they are still challenged by the fact that forcing factors can vary in space and time. 
Do different forcings result in distinct spatial morphological patterns across

\subsection{The delta as a network through time}

There are a couple of ways in which deltas can be represented as networks through time; the first is the application of the analyses above as a function 
of time to determine how connectivity patterns change as a function of autocan be analyzed to quantify how the configuration of channels and islands reorganizes itself over time. For example, the results of numerical or physical experiments can be analyzed to capture channel mobility and reworking of the delta surface with metrics such as channel instantaneous planform change, chanKim et al., 2010; Wickert et al., 2013; Liang et al., 2016). In addition, any of the channel and island metrics discussed in the previous sections can be analyzed over time. This type of analysis can be also performed in real systems when the available data cover a large enough time span. Several studies on the Niger Delta, for example, have quantified changes in land use and coastline dynamics (Onojeghuo and Blackburn, 2011; Kuenzer et al., 2014) in response to anthropogenic disturbance.

Another way of thinking about the delta as a network through time is via the imprint of its past dynamics in the stratigraphic record; time is thus captured along the vertical axis. Although boundary conditions can change over time, and thus surface patterns will not always be good indicators of the subsurface structure, spatial correlations between the surface morphology and the subsurface structure have been qualitatively assessed in systems such as the GBMD (Goodbred et al., 2003; Pickering et al., 2014; Wilson and Goodbred, 2015).

Whether or not surface patterns are good indicators of the subsurface structure, there is much to be gained by developing approaches to quantitatively assess the connectivity (or lack of) of surface and subsurface patterns. As noted above in the case of channel-island connectivity, metrics to quantify surfacesubsurface connectivity are lacking (Liang et al., 2016). A first step in this direction is the sedimentograph, proposed by Liang et al. (2016), based on the metric net:gross used in the hydrocarbon industry. This metric measures the deposited coarse sediment fraction and it can be computed spatially (over the whole network or along transects, e.g., distance from the shoreline) and over time (at one fixed location). 

agreement with changes in the surface patterns; in finer sediment deltas, where channels are likely to create new pathways on the floodplain, the sand fraction increases over time, while it decreases in coarser sediment deltas where channels tend to reoccupy existing pathways allowing mud deposition in the floodplain 575 between active channels. This knowledge can also be used to interpret deposits from cores collected in the field. Liang et al. (2016), for example, compared their modeling results to cores collected at WLD to quantify spatial and temporal deposition patterns. Given the availability of data from physical experiments, such as the ones performed in the Jurassic Tank (Paola et al., 2001) and other connection between surface patterns and the stratigraphic record.

Another notable example of surface-subsurface investigation is the study of van Dijk et al. (2016) in the Sutlej-Yamuna plain of northwest India. By relying on remotely sensed and wells data, the authors quantified the linkages Delta processes cover a wide range of spatial and temporal scales, resulting in couplings and feedbacks often referred to as complex and nonlinear. Despite their relevance to a quantitative understanding of delta functioning, delta couplings have not been quantified. The analysis of process couplings pertains to 595 cases above. The delta can be represented conceptually as a network of variables (e.g., discharge, wind, sediment flux) that act as nodes, and of couplings as network links. The adjacency matrix in this case will include directionality (the direction of the flow of information between two variables) and weights (the 
strength of the flow of information).

Ruddell and Kumar (2009a,b) quantified couplings and feedbacks among eco-hydrologic variables measured at a FLUXNET tower using statistical metrics developed in the field of communication theory, in particular mutual information and transfer entropy (Schreiber, 2000). This statistical method measures the reduction in the uncertainty of the current state of a variable due to knowledge of the history of another variable that is not already contained in the history of the variable itself (Ruddell and Kumar, 2009a). In their analysis, the authors were able to characterize couplings of ecohydrological variables in strength, directionality, scale, and statistical significance.

Recent work on the WLD has suggested that delta dynamics (for example shoreline hydrodynamics and thus island flooding) are controlled by discharge, wind, and tides (Geleynse et al., 2015). These environmental factors exert controls on the water surface elevation of the same order of magnitude despite the fact that the system is commonly considered river dominated. Thus, wind and tides contribute to the transport of sediment and nutrients with implications for land building and potential denitrification in delta islands (Hiatt and Passalacqua, 2015). Discharge will likely control inundation on longer time scales, on the order of weeks, while a forcing such as wind will affect water levels on much shorter (daily) scales.

20 An information theory approach, similar to the one used in the analysis of Ruddell and Kumar (2009a,b) could be used to quantify couplings in delta systems. A first step in this direction has been taken by Sendrowski et al. (2014) and Sendrowski (2015) who applied transfer entropy to the problem of island inundation at the WLD via the analysis of water surface elevation time series collected over several months. In their work, the behavior of channels and islands was contrasted to quantify the larger effect that wind and tides have on island water levels with respect to channels. This analysis was also performed at several spatial locations to quantify how the spatial location of the island within the network affects couplings. The importance of spatial location within the delta prompts again the extension of the classic definition of a network as 
a set of nodes and links (whose spatial location does not matter) to the one of a geographic network where spatial location plays a role in the transport of matter, energy, and information.

\subsection{Summary of connectivity in river deltas}

${ }_{635}$ To summarize the ideas here presented, a schematic depicting structural, functional, and process connectivity is in Fig. 5. Primary and secondary channels (solid lines marked on the left channel, Fig. 5(a)) and the transition from subaerial to subaqueous levees (unconfined flow near the bay represented by solid arrows on the right channel, Fig. 5(a)) are elements of structural connectivity. Examples of functional connectivity are the changes in flow direction due to tides in channels and islands (dashed arrows) and the magnitude and extent of the overbank flow. Process connectivity captures the shared and transferred information (solid lines, Fig. 5(b)) among delta variables and can be quantified by computing information theory metrics (mutual information and transfer entropy) among relevant delta variables (e.g., water level, wind speed, discharge, turbidity, temperature). The variables can be measured at several channel (triangles) and island (circles) locations and/or multiple locations within one island to quantify spatial differences in process connectivity.

\section{Discussion}

${ }_{650}$ In recent years significant interdisciplinary research has been focused on delta systems in response to the evidence of risk and increased vulnerability that characterize many coastal systems. These efforts have included numerical modeling, physical experiments, theoretical studies, field surveying, and remotely sensed imagery analysis with the goal of capturing the formation and evolution of delta systems under a variety of boundary conditions. Several of these studies have also developed metrics to quantify deltaic patterns and facilitate robust comparison of systems across environments and assessment of modeling results.

Connectivity in deltaic systems has not been quantified thus far; however, knowledge of how different portions interact with each other and of couplings 

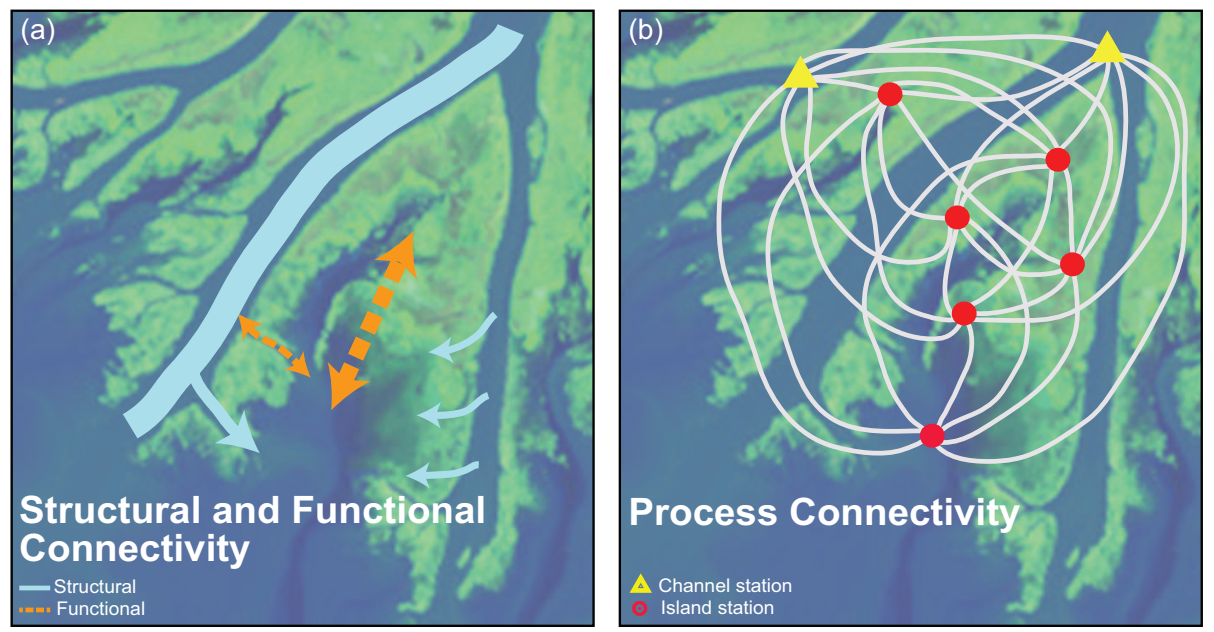

Figure 5: Connectivity in river deltas. (a) Elements of structural connectivity are primary and secondary channels (solid lines on the left channel) and unconfined flow close to the bay as levees transition from subaerial to subaqueous (solid arrows on the right channel). Functional connectivity manifests itself as changes in flow direction due to tides in islands and channels (dashed arrows) and in the magnitude and extent of the overbank flow. (b) A group of measurement stations located in channels (triangles) and islands (circles). Information shared or transferred (solid lines) among the measured variables can be quantified by computing mutual information and transfer entropy. Spatial variations among couplings can be quantified by measuring relevant delta variables at several locations within the delta (or within one island). 
and feedbacks among variables is needed to understand delta functioning and inform coastal restoration design. The restoration plan in act for the coast of Louisiana (LACPRA, 2012), for example, includes the design of engineered river diversions to reestablish the connectivity between channels and floodplains at strategic locations and promote land building. A connectivity analysis is important not only for quantifying the advantages of increased system's connectivity but also its disadvantages. Increased hydrological connectivity and residence times in wetlands represent favorable conditions to the spread of harmful algae blooms corresponding to deteriorated water quality conditions (Rivera-Monroy et al., 2010).

In this paper, I introduced the Delta Connectome as a framework for studying connectivity in deltaic systems through the representation of the delta as a network that defines the type of connectivity that can be captured. A network of channels is perhaps the most classic representation of a delta network, but only captures the main distributary network of channels. The analysis of field observations and remotely sensed data has pointed at islands, or the delta floodplain, as important portions of the network, whose connectivity with channels is of first-order importance for delta eco-morphodynamics. This finding has prompted the representation of the delta as a leaky network of channels and islands of mixed distributary/tributary character.

Metrics to quantify channel-island connectivity are scarse. A first step in this direction are the nourishment area and the distribution of fluxes at the shore. Further studies are also needed to formalize the conceptual diagram of channel-island connectivity (Figure 4) via modeling and analysis of other deltaic systems.

${ }_{85}$ Several environmental factors are active on deltas, often resulting in regions of distinct physical or statistical behavior. The representation of a delta as a network of regions and the quantification of their connectivity may inform about the large scale morphodynamics of a delta system by identifying, for example, strongly or weakly connected regions within the system. Further analysis in this direction is needed. Fundamental to describe this regional connectivity is 
the quantification of delta structure via spatial distribution metrics, rather than bulk metrics only. Characterizing the full probability density function of metrics rather than relying, for example, on a single descriptor such as a mean value, will allow the quantification of spatial heterogeneity.

The representation of a delta as a network through time can be used to analyze how the connectivity patterns of channels or channels and islands vary as a function of autogenic and allogenic processes. This analysis can also quantify changes in the system due to disturbances, given the availability of data over a large enough time span. An analysis of delta networks through time can also be performed by using the information in the stratigraphic record. Even if surface patterns are not always representative of the subsurface, better quantification of the connectivity between the surface and the subsurface is needed. Robust metrics are needed to quantify this type of connectivity.

The extension of the information theory approach of Sendrowski (2015) to include more delta variables, for example nutrient and sediment fluxes, offers the opportunity to create the process network of a delta, in analogy with the process network developed by Ruddell and Kumar (2009a,b) for eco-hydrology variables. Quantitative knowledge of delta couplings would allow the quantification of delta response to disturbance and change by comparing the process network of a healthy system to the one of a system under change. A similar analysis performed by Ruddell and Kumar (2009a) captured the effect of a drought by measuring reduced couplings in the process network. In order to build the process network of a delta system, field observations of water, sediment, and nutrient fluxes as well as water temperature and meteorological data are needed at fine temporal resolution and over a spatial extent that covers the domain of interest. Field observatories as the one established at the WLD can provide this type of information.

Most of the studies cited in this paper have relied on the analysis of one or a handful of delta systems due to practical difficulties in extracting many networks. The inherent complexity of distinguishing land and water in areas subject to frequent inundation and the lack of steep gradients to guide the 
extraction based on classic steepest descent approaches make the extraction of delta networks challenging. Recent developments in image processing offer robust solutions to this problem; the multi-scale singularity approach of Isikdogan et al. (2015) has been successful in extracting channel networks in coastal systems. While more work is needed in ensuring the connectivity of the extracted network, the procedure is robust and has already been applied to other systems including numerical modeling results (Liang et al., 2016).

There are remaining portions of deltaic systems so far not fully explored, for example the connectivity of surface water and groundwater. A first step in this direction is the analysis of field observations collected at WLD (O'Connor and Moffett, 2015) to understand surface water-groundwater connectivity in a young evolving delta, as well as work in older systems such as the finding of paleochannels as conduits for groundwater in the Mississippi River Delta (Kolker et al., 735 2013). The study of Sawyer et al. (2015) analyzed surface water-groundwater connectivity numerically. Further work is needed to fully quantify surface watergroundwater connectivity at the network scale and its implications on water and solutes transport in coastal systems.

Another area to be explored is the role of vegetation in the formation and evolution of deltaic systems and how it relates to hydrological connectivity. Knowledge on the role of vegetation in deltaic processes has come thus far from field observations, although recent numerical modeling studies have included vegetation and analyzed its effect on delta sedimentation (Nardin and Edmonds, 2014).

Overall, this study points at several characteristics of delta systems that make them distinct with respect to classic complex network representations. Delta networks may be leaky and characterized by the exchange of matter, energy, and information between channels and their surroundings. These networks are geographic, rather than purely topologic, meaning that physical location within the system matters rather than topological connectivity only. Lastly, delta networks evolve over time by reconfiguring themselves in response to avulsions or similar processes or changing transport directions in response to periodic 
tidal forcings. These characteristics suggest that the model of nodes and links mathematically quantified by an adjacency matrix will not be applicable in all cases, opening the door to the development of new mathematical approaches of network analysis.

\section{Conclusions}

Coastal restoration efforts require quantitative knowledge of connectivity in delta systems. Connectivity can be thought of as physical linkages among different portions of the delta, for example channels and wetlands or surface and subsurface, and process connectivity (couplings among delta variables).

In this paper I proposed a framework, called Delta Connectome, for studying connectivity in delta systems by analyzing representations of a delta system as a network (physical or conceptual). Research efforts, mostly recent, were reviewed and cast within this framework. Besides the classic representation of the delta as a network of channels, recent research points at the need of including islands (wetlands) within the hydrological network of a delta as significant fluxes are transferred from channels to islands. This finding has important implications both for the delivery of sediment to island interiors as well as the potential for nutrient reduction in delta islands given the longer travel times associated with flow paths through islands. Another relevant type of connectivity is the one between the surface and the subsurface, to connect surface patterns to the past dynamics imprinted in the stratigraphic record. More work is needed to formalize recent findings and also quantify other types of connectivity in the system such as the one of surface water-groundwater.

An approach based on information theory can be used to quantify delta couplings; methods such as transfer entropy are able to measure directionality, strength, statistical significance, and scale of process couplings. The approach could also lead to the quantification of delta response to change and disturbances.

Metrics to quantify connectivity appear to be lacking; recent efforts in this 
direction include the nourishment area, the distribution of fluxes at the shore, the sedimentograph, and transfer entropy. More work is needed in this direction to quantitatively compare deltas from different environments and robustly assess modeling results.

The connectivity analysis here performed points at important characteristics of delta networks (leaky, geographic, evolving in time) that do not fit the classic concept of network as a set of nodes and links, motivating the development of new mathematical approaches for studying delta networks.

\section{Acknowledgments}

I would like to acknowledge support from the National Science Foundation (grants CAREER/EAR-1350336 and FESD/EAR-1135427) and thank Chris Paola, Maarten Kleinhans, and David Mohrig for fruitful discussions on delta networks and feedback on an earlier version of this manuscript. Ellen Wohl and two anonymous reviewers are gratefully acknowledged for their constructive suggestions. A special thank you goes to my students and post-docs, particularly Matt Hiatt, Alicia Sendrowski, and Man Liang for their work and contributions to the Delta Connectome framework.

\section{References}

Alam M. Sea-Level Rise and Coastal Subsidence: Causes, Consequences, and Strategies. Dordrecht: Springer Netherlands, 1996. doi:10.1007/978-94-015-8719-8_9.

Alam MK, Hasan AKMS, Khan MR, Whitney JW. Geological Map of Bangladesh. Technical Report; Geological Survey of Bangladesh; 1990.

Ali GA, Roy AG. Revisiting hydrologic sampling strategies for an accurate assessment of hydrologic connectivity in humid temperate systems. Geography Compass 2009;3:350-74. doi:10.1111/j.1749-8198.2008.00180.x. 
Benda L, Andras K, Miller D, Bigelow P. Confluence effects in rivers: Interactions of basin scale, network geometry, and disturbance. Water Resources Research 2004b;40:W05402. doi:10.1029/2003WR005283.

Benda L, Leroy N, Miller D, Dunne T, Reeves G, Pess G, Pollock M. The network dynamics hypothesis: How channel networks structure river habitat. Bioscience 2004a;54(5):413-27. doi:10 . 1641/0006-3568 (2004) 054 [0413: TNDHHC] 2 . 0 . CO ; 2.

Biswal B, Marani M. Geomorphological origin of recession curves. Geophysical Research Letters 2010;37(24). doi:10.1029/2010GL045415; 124403.

Bracken LJ, Wainwright J, Ali GA, Tetzlaff D, Smith MW, Reaney SM, Roy AG. Concepts of hydrological connectivity: Research approaches, pathways and future agendas. Earth-Science Reviews 2013;119:17-34. doi:10.1016/j.earscirev . 2013.02.001.

Brakenridge GR, Syvitski JPM, Overeem I, Higgins SA, Kettner AJ, StewartMoore JA, Westerhoff R. Global mapping of storm surges and the assessment of coastal vulnerability. Natural Hazards 2013;66(3):1295-312. doi:10.1007/s11069-012-0317-z.

825 Burgess WG, Hoque MA, Michael HA, Voss CI, Breit GN, Ahmed KM. Vulnerability of deep groundwater in the bengal aquifer system to contamination by arsenic. Nature Geoscience 2010;3:83-7. doi:10.1038/ngeo750.

Caldwell RL, Edmonds DA. The effects of sediment properties on deltaic processes and morphologies: A numerical modeling study. Journal of Geophysical Research: Earth Surface 2014;119:961-82. doi:10.1002/2013JF002965.

Carvajal C, Steel R, Petter A. Sediment supply: the main driver of shelf-margin growth. Earth-Science Reviews 2009;96:221-48. doi:10.1016/j.earscirev.2009.06.008. 
Cazanacli D, Paola C, Parker G. Experimental steep, braided flow: Application to flooding risk on fans,. Journal of Hydraulic Engineering 2002;128(3):32230. doi:10.1061/ (ASCE) 0733-9429 (2002) 128:3(322).

Craig NJ, Turner RE, Day JW. Land loss in coastal louisiana (U.S.A.). Environmental Management 1979;3(2):133-44. doi:10 .1007/BF01867025.

Croke J, Fryirs K, Thompson C. Channel-floodplain connectivity during an extreme flood event: implications for sediment erosion, deposition, and delivery. Earth Surface Processes and Landforms 2013;38:1444-56. doi:10.1002/esp. 3430 .

Czuba JA, Foufoula-Georgiou E. A network-based framework for identifying potential synchronizations and amplifications of sediment delivery in river basins. Water Resources Research 2014;50:3826-51. doi:10.1002/2013WR014227.

Day G, Dietrich WE, Rowland JC, Marshall A. The depositional web on the floodplain of the Fly River, Papua New Guinea. Journal of Geophysical Research: Earth Surface 2008;113:F01S02. doi:10.1029/2006JF000622.

Day JW, Boesch DF, Clairain EJ, Kemp GP, Laska SB, Mitsch WJ, Orth K, Mashriqui H, Reed DJ, Shabman L, Simenstad CA, Streever BJ, Twilley RR, Watson CC, Wells JT, Whigham DF. Restoration of the Mississippi delta: Lessons from hurricanes Katrina and Rita. Science 2007;315(5819):1679-84. doi:10.1126/science.1137030.

Day JW, Britsch L, Hawes S, Shaffer G, Reed D, Cahoon D. Pattern and process of land loss in the Mississippi Delta: a spatial and temporal analysis of wetland habitat change. Estuaries and Coasts 2000;23(4):425-38. doi:10.2307/1353136.

Edmonds DA, Paola C, Hoyal DCJD, Sheets BA. Quantitative metrics that 860 describe river deltas and their channel network. Journal of Geophysical Research: Earth Surface 2011;116:F04022. doi:10.1029/2010JF001955. 
Edmonds DA, Slingerland RL. Mechanics of river mouth bar formation: Implications for the morphodynamics of delta distributary networks. Journal of Geophysical Research: Earth Surface 2007;112. doi:10.1029/2006JF000574; F02034.

Elliot T. Deltas. In: Reading HG, editor. Sedimentary Environments: Processes, Facies, and Stratigraphy. Blackwell Scientific Publication; 1986. p. 113-54.

Ericson JP, Vörösmarty CJ, Dingman SL, Ward LG, Meybeck M. Effective sea-level rise and deltas: Causes of change and human dimension implications. Global and Planetary Change 2006;50:63-82. doi:10.1016/j.gloplacha.2005.07.004.

Falcini F, Jerolmack DJ. A potential vorticity theory for the formation of elongate channels in river deltas and lakes. Journal of Geophysical Research: Earth Surface 2010;115(F4). doi:10.1029/2010JF001802; f04038.

875 Falcini F, Khan NS, Macelloni L, Horton BP, Lutken CB, McKee KL, Santoleri R, Colella S, Li C, Volpe G, et al. Linking the historic 2011 Mississippi River flood to coastal wetland sedimentation. Nature Geoscience 2012;5(11):803-7. doi:doi:10.1038/ngeo1615.

Fryirs K. (dis)Connectivity in catchment sediment cascades: a fresh look at the sediment delivery problem. Earth Surface Processes and Landforms 2013;38:30-46. doi:10.1002/esp.3242.

Gagliano SM, Meyer-Arendt KJ, Wicker KM. Land loss in the Mississippi River deltaic plain. Transactions of the Gulf Coast Association of Geological Societies 1981;31(4):295-300.

Galloway WE. Process framework for describing the morphologic and stratigraphic evolution of deltaic depositional systems. In: Broussard ML, editor. Deltas: Models for Exploration. Houston Geological Society, Houston, TX; 1975. p. 87-98. 
Ganti V, Paola C, Foufoula-Georgiou E. Kinematic controls on the geometry of the preserved cross sets. Journal of Geophysical Research: Earth Surface 2013;118(3):1296-307. doi:10.1002/jgrf .20094.

Geleynse N, Hiatt M, Sangireddy H, Passalacqua P. Identifying environmental controls on the shoreline of a natural river delta. Journal of Geophysical Research: Earth Surface 2015;120. doi:doi:10.1002/2014JF003408.

Geleynse N, Storms JEA, Stive MJF, Jagers HRA, Walstra DJR. Modeling of a mixed-load fluvio-deltaic system. Geophysical Research Letters 2010;37(5):L05402.

Geleynse N, Voller VR, Paola C, Ganti V. Characterization of river delta shorelines. Geophysical Research Letters 2012;39:L17402. doi:10.1029/2012GL052845.

Giosan L, Syvitsky J, Constantinescu S, Day J. Protect the world's deltas. Nature 2014;516(7529):31-3. doi:10.1038/516031a.

Goodbred SLJ, Kuehl SA, Steckler MS, Sarker MH. Controls on facies distribution and stratigraphic preservation in the Ganges905 Brahmaputra delta sequence. Sedimentary Geology 2003;155(3-4):301-16. doi:10.1016/S0037-0738(02)00184-7.

Gupta VK, Mantilla R, Troutman BM, Dawdy D, Krajewski WF. Generalizing a nonlinear geophysical flood theory to medium-sized river networks. Geophysical Research Letters 2010;37(11). doi:10.1029/2009GL041540; 111402.

Gupta VK, Mesa O. Runoff generation and hydrologic response via channel network geomorphology - Recent progress and open problems. Journal of Hydrology 1988;102:3-28.

Hart B. Delta front estuaries. In: Perillo GME, editor. Geomorphology and Sedimentology of Estuaries. Developments in Sedimentology. Elsevier Science, Amsterdam, The Netherlands; 1995. p. 87-98. 
Heckmann T, Schwanghart W, Phillips JD. Graph theory - recent developments of its application in geomorphology. Geomorphology 2015;243:130-46. doi:10.1016/j.geomorph.2014.12.024.

Helland-Hansen W, Martinsen OJ. Shoreline trajectories and sequences: description of variable depositional-dip scenarios. Journal of Sedimentary Research 1996;66(4):670-88.

Hiatt M, Passalacqua P. Hydrological connectivity in river deltas: The firstorder importance of channel-island exchange. Water Resources Research 2015;51. doi:10.1002/2014WR016149.

Higgins S, Overeem I, Tanaka A, Syvitski JPM. Land subsidence at aquaculture facilities in the Yellow River delta, China. Geophysical Research Letters 2013;40:3898-902. doi:10.1002/grl.50758.

Horton BP, Rahmstorf S, Engelhart SE, Kemp AC. Expert assessment of sealevel rise by AD 2100 and AD 2300. Quaternary Science Reviews 2014;84:1-6. doi:10.1016/j.quascirev.2013.11.002.

Hoyal D, Sheets BA. Morphodynamic evolution of experimental cohesive deltas. Journal of Geophysical Research: Earth Surface 2009;114. F02009.

Isikdogan F, Bovik AC, Passalacqua P. Automatic analysis of channel networks on remotely sensed images by singularity analysis. IEEE Geoscience and Remote Sensing Letters 2015;99:1-4. doi:10.1109/LGRS . 2015. 2458898.

Jerolmack DJ. Conceptual framework for assessing the response of delta channel networks to Holocene sea level rise. Quaternary Science Reviews 2009;28(1718):1786 -800. doi:http://dx.doi.org/10.1016/j.quascirev.2009.02.015.

Jerolmack DJ, Swenson J. Scaling relationships and evolution of distributary networks on wave-influenced deltas. Geophysical Research Letters 2007;34(23). doi:10.1029/2007GL031823; 123402. 
Jevrejeva S, Moore JC, Grinsted A, Matthews AP, Spada G. Trends and acceleration in global and regional sea levels since 1807. Global and Planetary Change 2014;113:11-22. doi:10.1016/j.gloplacha.2013.12.004.

Kesel RH. The role of the Mississippi River in wetland loss in southern Louisiana, U.S.A. Environmental Geology 1989;13(3):183-93. doi:10.1007/BF01665368.

Kiffney PM, Greene CM, Hall JE, Davis JR. Tributary streams create spatial discontinuities in habitat, biological productivity, and diversity in mainstream rivers. Canadian Journal of Fisheries and Aquatic Sciences 2006;63:2518-30. doi:10.1139/F06-138.

Kim W, Dai A, Muto T, Parker G. Delta progradation driven by an advancing sediment source: Coupled theory and experiment describing the evolution of elongated deltas. Water Resources Research 2009;45(6). doi:10.1029/2008WR007382; w06428.

Kim W, Sheets BA, Paola C. Steering of experimental channels by lateral basin tilting. Basin Research 2010;22(3):286-301. doi:10.1111/j.1365-2117.2009.00419.x.

Kleinhans MG, Ferguson RI, Lane SN, Hardy RJ. Splitting rivers at their seams: bifurcations and avulsion. Earth Surface Processes and Landforms 2013;38(1):47-61. doi:10.1002/esp. 3268.

Kolker AS, Cable JE, Johannesson KH, Allison MA, Inniss LV. Pathways and processes associated with the transport of ground965 water in deltaic systems. Journal of Hydrology 2013;498:319-34. doi:http://dx.doi.org/10.1016/j.jhydrol.2013.06.014.

Kuenzer C, Klein I, Ullmann T, Foufoula-Georgiou E, Baumhauer R, Dech S. Remote sensing of river delta inundation: exploiting the potential of coarse spatial resolution, temporally-dense MODIS time series. Remote Sensing 2015;7:8516-42. doi:10.3390/rs70708516. 
Kuenzer C, van Beijma S, Gessner U, Dech S. Land surface dynamics and environmental challenges of the Niger Delta, Africa: Remote sensing-based analyses spanning three decades (1986-2013). Applied Geography 2014;53:354-68. doi:10.1016/j. apgeog. 2014.07.002.

LACPRA . Louisiana's Comprehensive Master Plan for a Sustainable Coast. Technical Report; The State of Louisiana; 2012.

Larsen LG, Choi J, Nungesser MK, Harvey JW. Directional connectivity in hydrology and ecology. Ecological Applications 2012;22(8):2204-20. doi:10.1890/11-1948.1.

Lesser GR, Roelvink JA, van Kester JATM, Stelling GS. Development and validation of a three-dimensional morphological model. Coastal Engineering 2004;51(89):883-915. doi:http://dx.doi.org/10.1016/j. coastaleng. 2004.07.014.

Liang M, Geleynse N, Edmonds DA, Passalacqua P. A reduced-complexity model for river delta formation - Part II: Assessment of the flow routing scheme. Earth Surf Dynam 2015a;3:87-104. doi:10.5194/esurf-3-87-2015.

Liang M, Van Dyk C, Passalacqua P. Quantifying the response of river deltas to relative sea-level rise - assessment and application of a reduced-complexity model. Journal of Geophysical Research: Earth Surface 2016;121(2):465-96. doi:10.1002/2015JF003653.

Liang M, Voller VR, Paola C. A reduced-complexity model for river delta formation - Part I: Modeling deltas with channel dynamics. Earth Surface Dynamics 2015b;3:67-86. doi:10.5194/esurf-3-67-2015.

Lowe WH, Likens GE, Cosentino GJ. Self-organization in streams: The relationship between movement behavior and body condition in a headwater salamander. Freshwater Biology 2006;51:2052-62. doi:10.1111/j.1365-2427.2006.01635.x. 
Marra WA, Kleinhans MG, Addink EA. Network concepts to describe channel importance and change in multichannel systems: test results for the Jamuna River, Bangladesh. Earth Surface Processes and Landforms 2013;doi:10.1002/esp.3482.

Martin J, Sheets B, Paola C, Hoyal D. Influence of steady base-level rise on channel mobility, shoreline migration, and scaling properties of a cohesive experimental delta. Journal of Geophysical Research: Earth Surface 2009;114(F3). doi:10.1029/2008JF001142; f03017.

Michael HA, Voss CI. Evaluation of the sustainability of deep groundwater as an arsenic-safe resource in the bengal basin. Proceedings of the National Academy of Sciences 2008;105(25):8531-6. doi:10.1073/pnas. 0710477105.

Miller GR, Cable JM, McDonald AK, Bond B, Franz TE, Wang L, Gou S, Tyler AP, Zou CB, Scott RL. Understanding ecohydrological connectivity in savannas: a system dynamics modeling approach. Ecohydrology 2012;5:20020. doi:10.1002/eco. 245.

Muto T. Shoreline autoretreat substantiated in flume experiments. Journal of Sedimentary Research 2001;71:246-54. doi:10.1306/091400710246.

Nardin W, Edmonds DA. Optimum vegetation height and density for inorganic sedimentation in deltaic marshes. Nature Geoscience 2014;7:722-6. doi:10.1038/NGE02233.

Newman MEJ. Networks: An Introduction. New York, NY: Oxford University Press Inc., 2010.

Newman MEJ, Barabasi AL, Watts DJ. The Structure and Dynamics of Networks. Princeton, New Jersey: Princeton University Press, 2006.

O'Connor MT, Moffett KB. Groundwater dynamics and surface watergroundwater interactions in a prograding delta island, Louisiana, USA. Journal of Hydrology 2015;524:15-29. doi:10.1016/j . jhydrol.2015.02.017. 
Onojeghuo AO, Blackburn GA. Forest transition in an ecologically important region: Patterns and causes for landscape dynamics in the Niger Delta. Ecological Indicators 2011;11:1437-46. doi:10.1016/j .ecolind.2011.03.017.

Paola C, Mullin J, Ellis C, Mohrig DC, Swenson JB, Parker G, Hickson T, Heller PL, Pratson L, Syvistki J, Sheets B, Strong N. Experimental stratigraphy. GSA Today 2001;11(7):4-9.

Paola C, Twilley RR, Edmonds DA, Kim W, Mohrig D, Parker G, Viparelli E, Voller VR. Natural processes in delta restoration: application to the Mississippi delta. Annual Review of Marine Science 2011;3:67-91. doi:10.1146/annurev-marine-120709-142856.

Passalacqua P, Belmont P, Staley DM, Simley JD, Arrowsmith JR, Bode CA, Crosby C, DeLong SB, Glenn NF, Kelly SA, Lague D, Sangireddy H, Schaffrath K, Tarboton DG, Wasklewicz T, Wheaton JM. Analyzing high resolution topography for advancing the understanding of mass and energy transfer through landscapes: A review. Earth-Science Reviews 2015;148:174 -93. doi:10.1016/j. earscirev.2015.05.012.

Passalacqua P, Lanzoni S, Paola C, Rinaldo A. Geomorphic signatures of deltaic processes and vegetation: The Ganges-Brahmaputra-Jamuna case study. Journal of Geophysical Research: Earth Surface 2013;118(3):1838-49. doi:10.1002/jgrf. 20128.

Persits FM, Wandrey CJ, Milici RC, Manwar A. Digital Geologic and Geophysical Data of Bangladesh. Open File Report 97-470H; U.S. Geological Survey; 2001.

Pethick J, Orford JD. Rapid rise in effective sea-level in southwest Bangladesh: Its causes and contemporary rates. Global and Planetary Change 2013;111:237-45. doi:10.1016/j.gloplacha. 2013.09.019.

Phillips JD, Schwanghart W, Heckmann T. Graph theory 
in the geosciences. Earth-Science Reviews 2015;143:147-60. doi:10.1016/j.earscirev. 2015.02.002.

Pickering JL, Goodbred SL, Reitz MD, Hartzog TR, Mondal DR, Hossain MS.

Rowland JC, Dietrich WE, Day G, Parker G. Formation and maintenance of single-thread tie channels entering floodplain lakes: Observations from three diverse river systems. Journal of Geophysical Research: Earth Surface 2009;114. doi:10.1029/2008JF001073; F02013.

Rowland JC, Dietrich WE, Stacey MT. Morphodynamics of subaqueous levee formation: Insights into river mouth morphologies arising from ex- 
Seybold H, Andrade JS, Herrmann HJ. Modeling river delta formation. Proceedings of the National Academy of Sciences 2007;104(43):16804-9. doi:10.1073/pnas. 0705265104.

Seybold HJ, Molnar P, Singer HM, Andrade JS, Herrmann HJ, Kinzelbach doi:10.1029/2009JF001248; f03012. 
Shaw JB, Mohrig D. The importance of erosion in distributary channel network growth, Wax Lake Delta, Louisiana, USA. Geology 2014;42:31-4. doi:10.1130/G34751.1.

Shaw JB, Mohrig D, Wagner RW. Flow patterns and morphology of a prograding river delta. Journal of Geophysical Research: Earth Surface 2016;121(2):372-91. doi:10.1002/2015JF003570.

Shaw JB, Mohrig D, Whitman S. The morphology and evolution of channels on the Wax Lake Delta, Louisiana, USA. Journal of Geophysical Research: Earth Surface 2013;118:1562-84. doi:10.1002/jgrf . 20123.

Shaw JB, Wolinsky MA, Paola C, Voller VR. An image-based method for shoreline mapping on complex coasts. Geophysical Research Letters 2008;35:L12405. doi:10 . 1029/2008GL033963.

Sklar LS, Dietrich WE, Foufoula-Georgiou E, Lashermes B, Bellugi D. Do gravel bed river size distributions record channel network structure? Water Resources Research 2006;42:W06D18. doi:10.1029/2006WR005035.

Slingerland R, Smith ND. River avulsions and their deposits. Annual Review of Earth and Planetary Sciences 2004;32:257-85. doi:10.1146/annurev . earth.32.101802.120201.

Smart JS, Moruzzi VL. Quantitative properties of delta channel networks. Technical Report; IBM Thomas J. Watson Res. Cent.; Yorktown, N.Y.; 1971.

Sporns O, Tononi G, Kötter R. The human connectome: A structural description of the human brain. PLOS Computational Biology 2005;1(4):e42. doi:10.1371/journal/pcbi.0010042.

Sverre H, Gary JH, William HH, Erik PJ, Ron JS. Shelf edge and shoreline trajectories, a dynamic approach to stratigraphic analysis. Basin Research 2009;21(5):445-53. doi:10.1111/j.1365-2117.2009.00432.x. 
Syvitski JP, Saito Y. Morphodynamics of deltas under the influence of humans. Global and Planetary Change 2007;57(34):261 -82. doi:http://dx.doi.org/10.1016/j.gloplacha.2006.12.001.

Syvitski JPM. The morphodynamics of deltas and their distributary channels. In: Parker G, Garcia M, editors. River, coastal, and estuarine morphodynamics. London: Taylor and Francis Group; 2006. p. 143-50. doi:10.1201/9781439833896. ch18.

Syvitski JPM, Kettner AJ, Overeem I, Hutton EWH, Hannon MT, Brackenridge GR, Day J, Vörösmarty C, Saito Y, Giosan L, Nicholls RJ. Sinking deltas due to human activities. Nature Geoscience 2009;2:681-6. doi:10.1038/ngeo629.

Tejedor A, Longjas A, Zaliapin I, Foufoula-Georgiou E. Delta channel networks. 1: A graph-theoretic approach for studying connectivity and steady state transport on deltaic surfaces. Water Resources Research 2015a;51. doi:10.1002/2014WR016577.

Tejedor A, Longjas A, Zaliapin I, Foufoula-Georgiou E. Delta channel networks. 2: Metrics of topologic and dynamic complexity for delta comparison, physical inference, and vulnerability assessment. Water Resources Research 2015b;51. doi:10.1002/2014WR016604.

Temmerman S, Kirwan ML. Building land with a rising sea. Science 2015;349:588-9. doi:10.1126/science.aac8312.

Trigg MA, Bates PD, Wilson MD, Schumann G, Baugh C. Floodplain channel morphology and networks of the middle Amazon River. Water Resources Research 2012;48. doi:10.1029/2012WR011888; W10504.

van Dijk WM, Densmore AL, Singh A, Gupta S, Sinha R, Mason PJ, Joshi SK, Nayak N, Kumar M, Shekhar S, Kumar D, Rai SP. Linking the morphology of fluvial fan systems to aquifer stratigraphy in the sutlej-yamuna plain of northwest india. Journal of Geophysical Research: Earth Surface 2016;doi:10.1002/2015JF003720; 2015JF003720. 
Wang L, Zou C, O'Donnell F, Good S, Franz T, Miller GR, Caylor KK, Cable JM, Bond B. Characterizing ecohydrological and biogeochemical connectivity across multiple scales: a new conceptual framework. Ecohydrology 2012;5:221-33. doi:10.1002/eco.187.

Western AW, Bloschl G, Grayson RB. Toward capturing hydrologically significant connectivity in spatial patterns. Water Resources Research 2001;37(1):83-97. doi:10.1029/2000WR900241.

Wickert AD, Martin JM, Tal M, Kim W, Sheets B, Paola C. River channel lateral mobility: metrics, time scales, and controls. Journal of Geophysical Research: Earth Surface 2013;118(2):396-412. doi:10.1029/2012JF002386.

Wilson CA, Goodbred SL. Construction and maintenance of the Ganges-Brahmaputra-Meghna delta: linking process, morphology, and stratigraphy. Annual Review of Marine Science 2015;7:67-88. doi:10.1146/annurev-marine-010213-135032.

Wilson CA, Goodbred SL, Sams S, Small C. Anthropogenic changes to the tidal channel network, sediment rerouting, and social implications in southwest Bangladesh. In: American Geophysical Union AGU Fall Meeting, San Francisco, CA. 2015. p. GC44C-05.

${ }_{1180}$ Wolinsky MA, Edmonds DA, Martin J, Paola C. Delta allometry: Growth laws for river deltas. Geophysical Research Letters 2010;37. doi:10.1029/2010GL044592; L21403.

Wright LD, Coleman JM. River delta morphology: Wave climate and the role of the subaqueous profile. Science 1972;176:282-4.

1185 Wright LD, Coleman JM. Variations in morphology of major river deltas as functions of ocean wave and river discharge regimes. American Association of Petroleum Geologists Bulletin 1973;57:370-98. 
Zaliapin I, Foufoula-Georgiou E, Ghil M. Transport on river networks: A dynamic tree approach. Journal of Geophysical Research: Earth Surface 2010;115(F2). doi:10.1029/2009JF001281; f00A15. 